\title{
Experimental modeling of mechanical characteristics in living elastic bodies with acoustic wave action
}

\begin{abstract}
Aims: To realize a negative acoustic effect on the bodies of insect larvae.

Methods: The study of the acoustic and mechanical characteristics of the force of living bodies led to the conclusion that it is possible to exert a detailed effect on the bodies of the larvae of harmful insects with acoustic fields. It is necessary to know the mass, stiffness and resonance frequency of these bodies.
\end{abstract}

Results: A technique for determining the resonant frequency of the larvae of harmful insects has been developed. The study is based on the assumption that the shape of the body of the larva is close to the shape of a uniform cylindrical shaft. The organs of the larvae are loaded into a special device. The processing of the experimental data made it possible to calculate the modulus of elasticity and rigidity of the body of the larva.
Volume 2 Issue 4 - 2018

\author{
Galyna I Sokol, Tatyana L Savchuk, Tatyana A \\ Rybalka, Anatolii O Babych \\ Oles Honchar Dniprovsk National University, Ukraine
}

Correspondence: Galyna I Sokol, Oles Honchar Dniprovsk National University, Ukraine, Email gsokol@ukr.net

Received: December 05, 2018 | Published: July 25, 2018

Keywords: negative acoustic effect, insect larvae, mass, stiffness, resonance frequency of the bodies

\section{Introduction}

The acoustic field has a positive and negative impact on living organisms. In this case, the coincidence of the resonant frequencies of individual organs of living organisms with certain frequencies of acoustic fields leads, with high values of the amplitudes of oscillations, to negative effects. ${ }^{1}$ An important point in the study of acoustic effects on the organs of living organisms is obtaining reliable data on the mechanical characteristics of these organs: stiffness, modulus of elasticity, relative elongation of the body. ${ }^{2}$ Under the influence of external mechanical disturbances in the form of acoustic vibrations, the body should be regarded as a system consisting of mechanical elements. They are characterized by inertial, elastic, damping properties. An interesting method is the destruction of harmful insects by acoustic waves. To perform a negative acoustic impact on the body of insects, you need to know the mass, stiffness and resonant frequency of their body. The rupture of tissues and the biological death of harmful insects when exposed to acoustic vibrations indicate that a resonant frequency of the body or organ has been found. ${ }^{3}$ Equations describing the vibrational motion of the body of a biological object or its individual parts are recorded taking into account the approximations and assumptions adopted, the applicability limits of which are derived from the basic laws of the phenomena being studied. ${ }^{4}$ The behavior of a real mechanical system can be mathematically represented and described using models consisting of various viscous and elastic elements. If the behavior of the elastic body is simulated with the help of a spring, and the viscous body by a piston in a cylinder, then the equation of the vibrational motion of the body of a pest insect (in

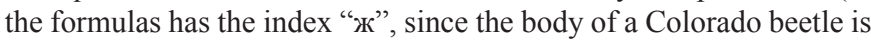
considered) as a viscoelastic oscillatory system has the form:

$$
\left.\ddot{\delta}+C_{b} / m_{b}\right) \dot{\delta}+\left(k_{b} / m_{b}\right) \delta=a(t)
$$

Where $m_{b}$-mass, $\mathrm{c}_{b}$-coefficient of damping, $\mathrm{k}_{b}$-coefficient of rigidity, $\delta$-deformation, and $\ddot{\delta}$-specified acceleration.

The resonance frequency of oscillations $\mathrm{f}_{b}$ of a viscoelastic body is defined as:

$$
f_{b}=1 / 2 \pi \sqrt{k_{b} / m_{b}}
$$

To develop a method of rupturing the bodies, organs or tissues of a biological object, one can, using a strong influence of an oscillatory nature.

\section{Main part}

The object of testing in this work was the larvae of the Colorado beetle. The parameters and characteristics were measured for each larva individually. Previously, an external examination was performed, which showed that the body of the larva formed to the age state when the head and legs appeared, and it has an oval-convex shape, widening from the head. During the experiments, the weight of the larva was determined, its length was measured, the diameter of the body in the maximum section. Then the body of the larva was installed in a special device (Figure 1). Loads were applied from top to bottom on the body of the larva by forces P1, P2, P3, P4, P5. The micrometer readings recorded changes in body size, that is, shortening of the body under the action of force (compression value). All indications were recorded and recorded in the measurement log. After exposure, an external examination of the body of the larva was carried out. The strength and measured values are listed in the table. The obtained data made it possible to calculate the elastic modulus and rigidity of the larval body as a homogeneous rod.

The experiments were carried out under external conditions: air temperature $28^{\circ} \mathrm{C}$, humidity $80 \%$. The following indicators were used for the measurements: the indicator of the watch type ИЧ 10 (the division price is $0.01 \mathrm{~mm}$, the permissible error is $\pm 0.005 \mathrm{~mm}$, the measuring range is $0-10 \mathrm{~mm}$ ); micrometer (division price $0.01 \mathrm{~mm}$, measuring range $0-25 \mathrm{~mm}$ ); Libra; tripod; calipers; ruler. The results of the measurements are shown in Table 1.

Table 1 indicates the following values: $\mathrm{G}$ - weight; 1-length of the body d-diameter of the maximum section; P - force of external influence; $\Delta \mathrm{l}$ is the absolute contraction. 


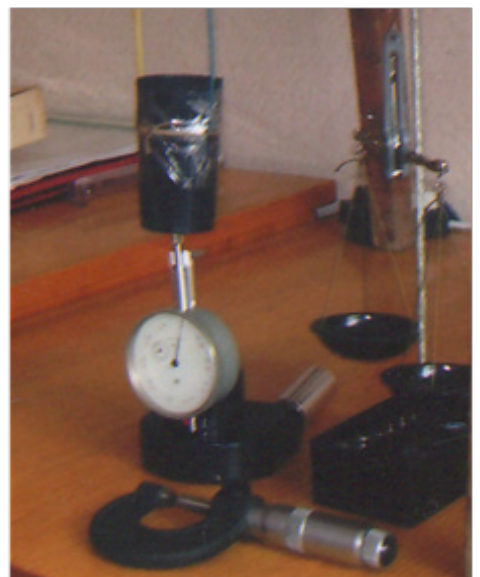

Figure I Installation for force action on the body of the larva.

The stiffness of the larva of the Colorado potato beetle is determined from expression

$$
C=\frac{P}{\Delta l}
$$

Where $\mathrm{P}$ is the force acting on the larva, and $\Delta \mathrm{l}$ is the absolute compression of the larva.

It is known [5] that for a body of cylindrical shape

\begin{tabular}{|c|c|c|c|c|c|c|c|c|}
\hline \multirow[t]{2}{*}{ № } & & & & $\begin{array}{l}P_{1}=20 x \\
10^{-6}, N\end{array}$ & $\begin{array}{l}P_{2}=25 x \\
10^{-6}, N\end{array}$ & $\begin{array}{l}P_{3}=30 x \\
10^{-6}, N\end{array}$ & $\begin{array}{l}P_{4}=35 x \\
10^{-6}, N\end{array}$ & $\begin{array}{l}P_{5}=40 x \\
10^{-6}, N\end{array}$ \\
\hline & $10^{-6}, \mathrm{~N}$ & $10^{-3}, \mathrm{~m}$ & $10^{-3}, \mathrm{~m}$ & $\Delta I_{1} \times 10^{-3}, \mathrm{~m}$ & $\Delta \mathrm{l}_{2} \times 10^{-3}, \mathrm{~m}$ & $\Delta \mathrm{l}_{3} \times 10^{-3}, \mathrm{~m}$ & $\Delta l_{4} \times 10^{-3}, \mathrm{~m}$ & $\Delta I_{5} \times 10^{-3} \mathrm{~m}$ \\
\hline I & 120 & 6,0 & 5,00 & 0,820 & 0,930 & 1,680 & 1,800 & 2,180 \\
\hline 2 & 100 & 9,0 & 6,00 & 0,640 & 0,875 & 1,190 & 1,610 & $\mathrm{I}, 840$ \\
\hline 3 & 150 & 10,0 & 7,00 & 0,630 & 0,755 & 1,500 & I,590 & 1,950 \\
\hline 4 & 110 & 7,5 & 5,10 & 0,620 & 0,860 & 1,180 & 1,620 & 1,820 \\
\hline 5 & 150 & 9,0 & 5,15 & 0,750 & 0,960 & 1,210 & 2,050 & 2,420 \\
\hline
\end{tabular}

Table 2 Results of calculation

\begin{tabular}{llllll}
\hline № & $\Delta l, \mathbf{m}$ & $\boldsymbol{C}, \mathbf{N} / \mathbf{m}$ & $\boldsymbol{F}, \mathbf{m}^{2}$ & $\boldsymbol{E}, \mathbf{P a}$ & $\boldsymbol{f}, \mathbf{H z}$ \\
\hline $\mathrm{I}$ & 2 & 3 & 4 & 5 & 6 \\
$\mathrm{I}$ & 0,00082 & 0,2393 & & 60,96 & 7,1088 \\
& 0,00093 & 0,2636 & & 67,17 & 7,4623 \\
& 0,00168 & 0,1752 & 0,0000196 & 44,63 & 6,0826 \\
& 0,0018 & 0,1907 & & 48,59 & 6,3468 \\
& 0,00218 & 0,18 & & 45,86 & 6,1658 \\
2 & 0,00064 & 0,3066 & & 65,09 & 8,8146 \\
& 0,000875 & 0,2802 & & 59,50 & 8,4275 \\
& 0,00119 & 0,2473 & 0,0000283 & 52,51 & 7,9171 \\
& 0,00161 & 0,2132 & & 45,27 & 7,3513 \\
& 0,00184 & 0,2133 & & 45,28 & 7,3519 \\
\hline
\end{tabular}

Citation: Sokol GI, Savchuk TL, Rybalka TA, et al. Experimental modeling of mechanical characteristics in living elastic bodies with acoustic wave action. MOJ App Bio Biomech. 2018;2(4):238-240. DOI: I0.15406/mojabb.2018.02.00073
Where $\mathrm{E}$ is the modulus of longitudinal elasticity, characterizing the rigidity of the material, that is, its resistance to elastic deformations, is calculated from expression

$$
E=\frac{C \times d}{F}
$$

Where $\mathrm{F}$ is the cross-sectional area of the larva, cylindrical

$$
F=\frac{\pi d^{2}}{4}
$$

The developed technique allowed determining the resonance frequency of the insect larva's body $f$, on the basis of the expression (5) analogous to the expression (1)

$$
f=1 / 2 \pi \sqrt{k / m}
$$

Where $\mathrm{c}$ is the rigidity of the body of the larva, $\mathrm{f}$ is the resonance frequency, $\mathrm{m}$ is the mass.

The resonance frequency $f$ of the larva is calculated from the expression (6) on the basis of the obtained stiffness values c (see column 3 in Table 2) and is represented by the values of $f$ in Table 2 (column 6).
Table I Indicators of measurements 
Table continued...

\begin{tabular}{|c|c|c|c|c|c|}
\hline № & $\Delta l, \mathrm{~m}$ & $C, \mathbf{N} / \mathbf{m}$ & $F, \mathrm{~m}^{2}$ & $E, P a$ & $f, \mathrm{~Hz}$ \\
\hline \multirow[t]{5}{*}{3} & 0,00063 & 0,3114 & & 56,67 & 7,2540 \\
\hline & 0,000755 & 0,3248 & & 59,10 & 7,4077 \\
\hline & 0,0015 & 0,1962 & 0,0000385 & 35,70 & 5,7577 \\
\hline & 0,00159 & 0,2159 & & 39,29 & 6,0399 \\
\hline & 0,00195 & 0,2012 & & 36,62 & 5,8310 \\
\hline \multirow[t]{5}{*}{4} & 0,00062 & 0,3164 & & 79,07 & 8,5389 \\
\hline & 0,00086 & 0,285 I & & 71,24 & 8,1051 \\
\hline & 0,00118 & 0,2494 & 0,0000204 & 62,32 & 7,5805 \\
\hline & 0,00162 & 0,2119 & & 52,95 & 6,9876 \\
\hline & 0,00182 & 0,2156 & & 53,87 & 7,0481 \\
\hline \multirow[t]{5}{*}{5} & 0,00075 & 0,2616 & & 64,76 & 6,6484 \\
\hline & 0,00096 & 0,2554 & & 63,23 & 6,5693 \\
\hline & 0,00121 & 0,2432 & 0,0000208 & 60,21 & 6,4106 \\
\hline & 0,00205 & 0,1675 & & 41,46 & 5,3193 \\
\hline & 0,00242 & 0,1621 & & 40,14 & 5,2342 \\
\hline
\end{tabular}

\section{Conclusion}

Experiments have been carried out, including measurements of the mechanical characteristics of the body of the larva of the Colorado potato beetle. Theresonance frequencies of the bodies of the larvae are obtained. On the basis of the results obtained, it is possible to give recommendations on the acoustic characteristics of the field, intended for the destructive effect on the bodies of the larvae.

\section{Acknowledgments}

None.

\section{Conflict of interest}

Author declares that there is no conflict of interest.

\section{References}

1. Sokol GI, Rybalka TA. Mekhanizm vozdejstviya akusticheskih kolebanijna serdechnuyu sistemu nasekomogo. Ekologiya ta noosferologiya. 2012;23(1-2):84-91.

2. Sokol GI, Rybalka TA. Elaboration and Investigtion of the Acoustic Method of Elimihation of Colorado Beetle /ASME/ IEEE International Conference on and Applications (MESA09). Tonik: Mechatronic and Embedded Systems MESA 09-10/Disigh Engineering. Technikal Conference Computers and Information in Engineering Conference DETC 2009.

3. Sokol GI, Rybalka TA. The acoustic method of Elimination of Colorado Beetle / Annual Meeting GAMM-2009, 8-15 February 2009, Gdansk, Poland: Book of Abstracts; 2009. p. 355.

4. Sokol GI, Rybalka TA. Vibracionnye vozdejstviyana vreditelej rastenij / International Conference Dynamical System Modelling and Stability Investigation 27-29 May, Kiyv: thesis of conference reports; 2009. p. 250. 